
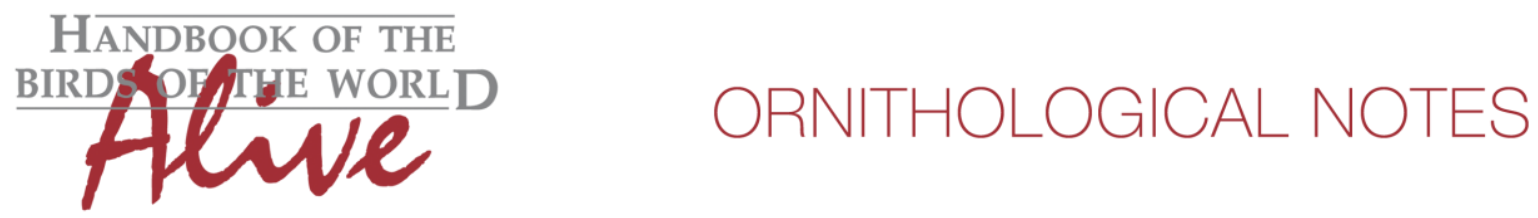

\title{
Notes on the vocalizations of Rusty-backed Spinetail (Cranioleuca vulpina)
}

Peter Boesman

In the following we briefly analyze and compare voice of the disjunct race dissita from Coiba Island Panama with the different South-American races of Rusty-backed Spinetail (Cranioleuca vulpina). We also try to quantify the extent of any vocal differences using the criteria proposed by Tobias et al. (2010), as a support for taxonomic review.

We have made use of sound recordings available on-line from Xeno Canto (XC).

\section{'Coiba Spinetail' C.v. dissita ( $n=4)$}

Song starts with a variable number of short notes before shifting to a series of longer emphasized notes. Initial notes downslurred, last notes almost flat in pitch and slightly burry (Fig. 1). (No stuttering, fading end as in other races, clearly higher in frequency, no nasal tone quality etc., apparently not commonly in duet).

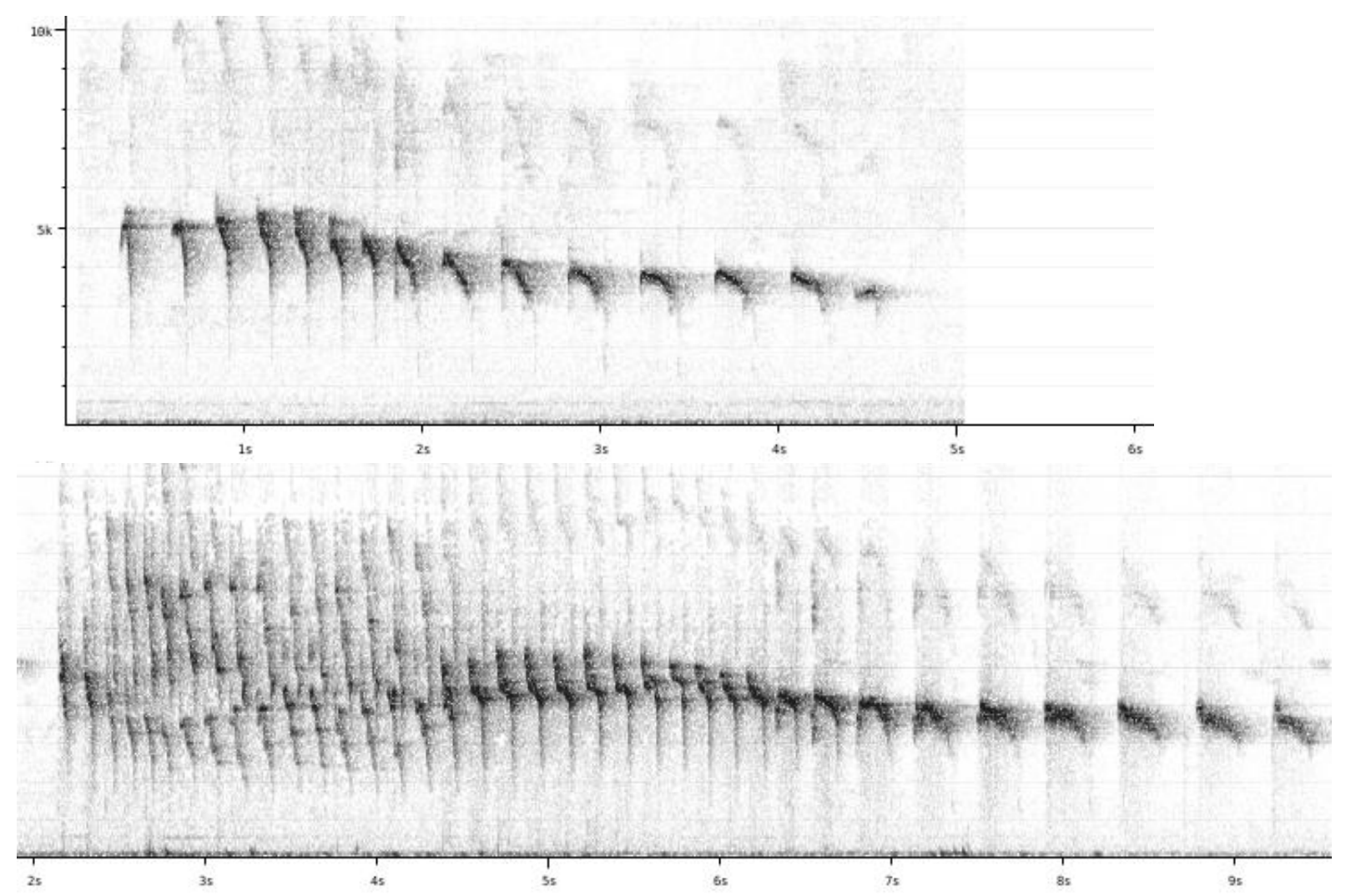

Figure 1: typical song of dissita (top) and excited after play-back (bottom)

Measurements:

Max. freq of all notes: $5200-5600 \mathrm{~Hz}$

Note length longest note: $0.20-0.29 \mathrm{~s}$ 

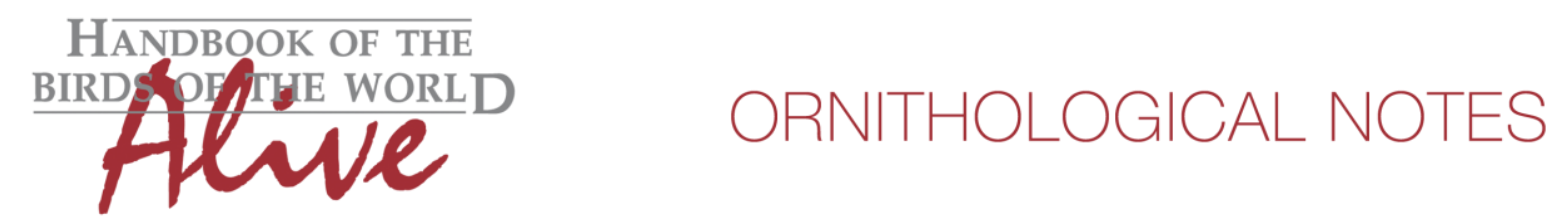

\section{Rusty-backed Spinetail (all other races)(8 recordings measured)}

Song is a loud descending stuttering series of nasal notes, typically preceded by a few accelerating introductory notes. All notes in the stuttering series have a characteristic curled shape. Notes usually become shorter towards the end of the stuttering series and decrease in amplitude. Song mostly given in asynchronous duet. Clearly nasal notes with 1st, 2nd and 3rd harmonic about equally loud, unlike dissita (Fig. 2).

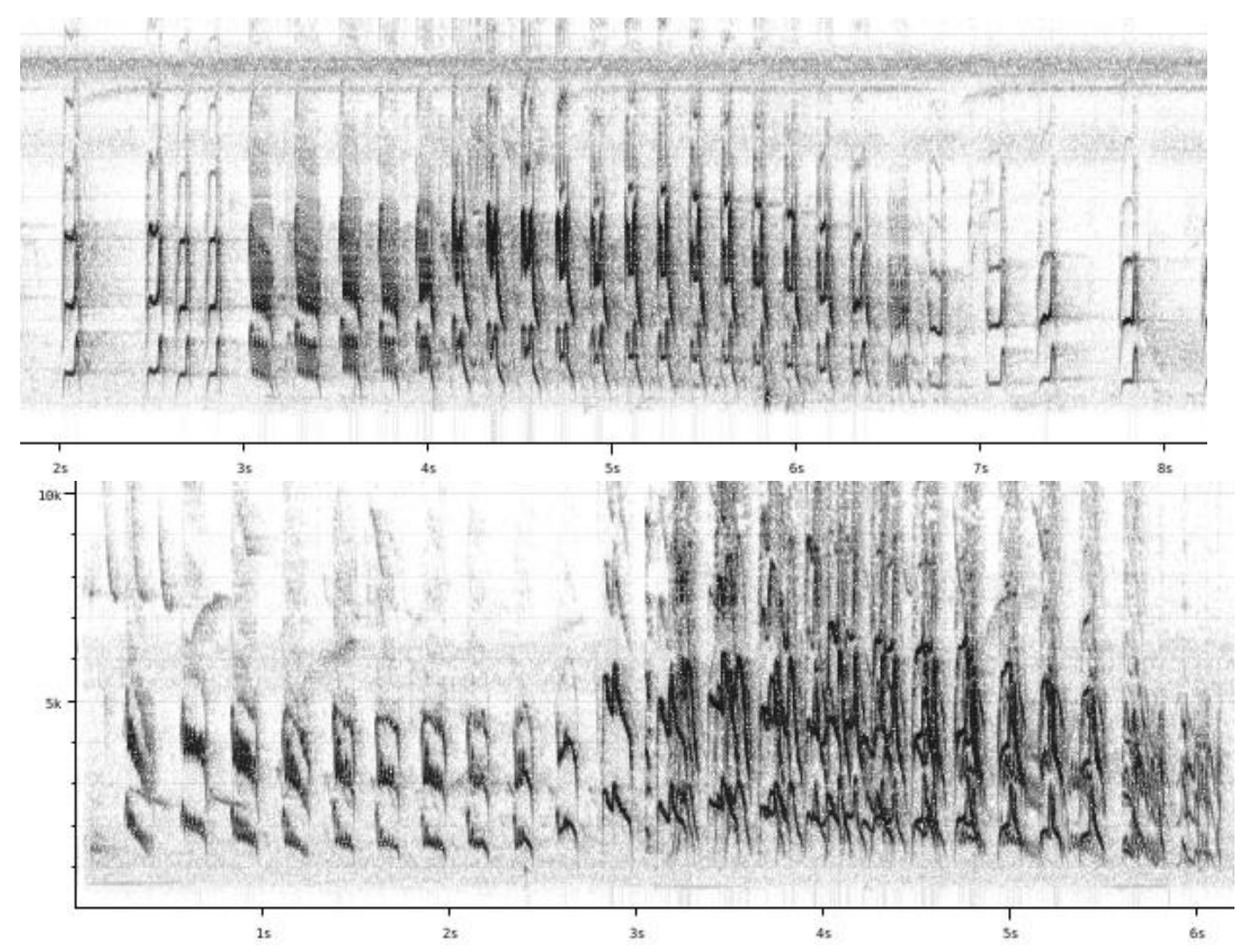

Figure 2: Typical song of South-American races (top) and duet (bottom)

Measurements:

Max. freq of all notes (base frequency): $2800-3380 \mathrm{~Hz}$

Note length longest note: $0.10-0.15 \mathrm{~s}$

Song of dissita thus is not a fading stuttering series as in C. vulpina, but on the contrary ends with longer emphasized slightly burry notes. Overall pitch is higher (highest max. frequency, score 3), longest notes are flat in pitch and distinctly longer (score 2-3) and note shape is different with much fainter harmonics (1-2). Not commonly in duet (1-2). When applying Topica criteria this would lead to a total vocal score of 5-6.

This note was finalized on 13th April 2015, using sound recordings available on-line at that moment. We would like to thank in particular the many sound recordists who placed their recordings for this species on XC. 


\section{References}

Tobias, J.A., Seddon, N., Spottiswoode, C.N., Pilgrim, J.D., Fishpool, L.D.C. \& Collar, N.J. (2010). Quantitative criteria for species delimitation. Ibis 152(4): 724-746.

\section{Recommended citation}

Boesman, P. (2016). Notes on the vocalizations of Rusty-backed Spinetail (Cranioleuca vulpina). HBW Alive Ornithological Note 101. In: Handbook of the Birds of the World Alive. Lynx Edicions, Barcelona. (retrieved from http://www.hbw.com/node/932006 on 22 July 2016). 